\title{
The Influence of Negative Surprise on Hedonic Adaptation
}

\author{
Ana Paula Kieling ${ }^{\prime}$ \\ University of Vale do Itajaí - Univali \\ Vinicius Andrade Brei ${ }^{\Omega}$ \\ Federal University of Rio Grande do Sul - UFRGS \\ Valter Afonso Vieira ${ }^{¥}$ \\ State University of Maringá - PPA/UEM
}

\begin{abstract}
After some time using a product or service, the consumer tends to feel less pleasure with consumption. This reduction of pleasure is known as hedonic adaptation. One of the emotions that interfere in this process is surprise. Based on two experiments, we suggest that negative surprise - differently to positive - influences with the level of pleasure foreseen and experienced by the consumer. Study 1 analyzes the influence of negative ( $v s$. positive) surprise on the consumer's post-purchase hedonic adaptation expectation. Results showed that negative surprise influences the intensity of adaptation, augmenting its strength. Study 2 verifies the influence of negative ( $v s$ positive) surprise over hedonic adaptation. The findings suggested that negative surprise makes adaptation happen more intensively and faster as time goes by, which brings consequences to companies and consumers in the post-purchase process, such as satisfaction and loyalty.
\end{abstract}

Keywords: Hedonic adaptation. Negative surprise. Consumption. Post-purchase. Experiment.

Received on 02/11/2015; Reviewed on 04/06/2015; Accepted on 06/16/2015; Divulgued on 05/02/2016.

*Author for correspondence:

${ }^{\dagger}$. Master of Business Administration by the Federal University of Santa Catarina UFSC.

Vínculo: PhD Student in Administration by the University of Vale do Itajaí - UNIVALI Endereço: Rua João Coan, 400 - Bairro Universitários, CEP: 88161-64, Biguaçu SC - Brazil

E-mail: anakieling@gmail.com Telefone: (48) 99001927
$\Omega$ Docteur em Sciences de Gestion pela École des Hautes Études Commerciales (HEC), França e

Doctor in Administration by the Federal University of Rio Grande do Sul UFRGS.

Vínculo: Administration graduate program school of management of

Federal University of Rio Grande do Sul - UFRGS.

Endereço: Rua Washington Luiz, 855,

sala 436 - CEP 90010-460 - Porto

Alegre - RS - Brazil

E-mail: brei@ufrgs.br

Telefone: (51) 83257777
${ }^{¥}$ Doctor in Administration by the University of Brasília - UnB.

Vínculo: State University of Maringá PPA/UEM.

Endereço: Av. Colombo, 5790 - Bloco C23 - Sala 15 - CEP 87020-900 -

Maringá - PR - Brazil

E-mail: valterafonsovieira@gmail.com

Telefone: (44) 98523351

Note from the Editor: This paper was accepted by Bruno Felix. 


\section{INTRODUCTION}

egardless of how much consumers like or feel good about a product or

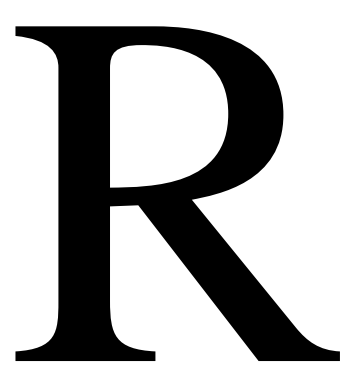
service, they tend to have less pleasure in consumption, a phenomenon known as hedonic adaptation (WANG; NOVEMSKY; DHAR, 2009). One of the emotions that interfere in the process of reducing pleasure, specifically on hedonic adaptation, is surprise. Literature shows that surprise interferes in human well-being asymmetrically (BAO; BOEHEM; LYUBOMIRSKY, 2011; 2012; BAUMEISTER; BRATSLAVSKY; FINKENAUER, 2001LYUBOMIRSKY, 2011) and that positive surprise postpones the reduction of pleasure caused by hedonic adaptation (BAO; BOEHEM; LYUBOMIRSKY, 2012). However, we do not know how the occurrence of a negative surprise during consumption influences the levels of hedonic adaptation foreseen and expected by the consumer. Therefore, there is a gap in the literature, bringing important theoretical and practical implications which this paper addresses.

Although advances have been achieved in understanding the role of positive surprise in human well-being (SHELDON; LYUBOMIRSKY, 2012), no evidence was found of the influence and the magnitude of the negative surprise in the hedonic adaptation process. Furthermore, little is known about the role of time interacting on the association between negative surprise and hedonic adaptation process. The premise of the effect of time is suggested by Diener, Lucas and Scollon (2006), who showed that the hedonic adaptation to negative events is slower than to positive events. In other words, people feel unhappy faster with the occurrence of a negative event in comparison with how fast they feel happy with the occurrence of a positive event of the same magnitude. Literature shows that negative events still tend to evoke physiological, cognitive, emotional and social responses which are more robust than neutral or positive events (TAYLOR, 1991; BAUMEISTER; BRATSLAVSKY; FINKENAUER, 2001; LYUBOMIRSKY, 2011). The analysis of negative effects and their asymmetry in relation to positive effects on the adaptive processes of the consumer is fundamental, because adaptive process impacts on relations between companies and customers.

To examine the influence and the asymmetric effects of negative surprise in the forecast and in the hedonic adaptation, we analyzed the literature on surprise and hedonic adaptation. Then, we propose a conceptual framework and hypotheses. Next, we tested the hypotheses based on two experimental studies, comparing the effects of negative surprise to positive 
surprise, at different moments in time and of repetition of consumption. The results of the two experiments showed the surprise effect and acceleration in time of the adaptation due to the negative surprise. It means that the cycle of consumption becomes faster with this mechanism. In addition to the theoretical implications that reinforce the asymmetric effects of surprise, we present the managerial implications of the research. The main implications are related with the effects on the post-purchase procedures, such as brand loyalty and satisfaction, since the negative experience can drive consumers away from a brand, leading them to consume from competitors.

\section{SURPRISE AND HEDONIC ADAPTATION}

Surprise is a neutral short-term emotion that usually occurs during the post-purchase stages (BAGOZZI; GOPINATH; NYER, 1999), carrying other emotions that bring positive and negative features to it. Negative surprise is the sum of micro emotions, such as fear, discontent and astonishment that arise from an unexpected experience (DERBAIX; VANHAMME, 2003). Watkins and Bazerman (2003) showed that many of the negative surprises that occur with consumers and businesses could be predicted by organizations from prior recognition of threats to processes and of the mobilization of necessary resources.

According to Wilson and Gilbert (2008), surprise is an important condition because it is directly related to attention and often. In other words, it means that the individual does not understand properly or does not expect a particular event or situation. For this reason, events or unexpected situations tend to trigger surprises of varying magnitudes. Mellers, Ritov and Schwartz (1999) evidenced that the more unexpected an event is, the greater the surprise for the individual, be it positive or negative. For Diener, Lucas and Scollon (2006), the hedonic adaptation related to negative surprises is slower than the hedonic adaptation to positive events because many cognitive effects are weakest when it comes to positive experiences (BAUMEISTER; BRATSLAVSKY; FINKENAUER, 2001). Depending on the magnitude of the negative surprise, Lyubomirsky (2011) commented that people might suffer losses in their well-being, sometimes never recovering fully.

Although literature on Psychology shows that negative events tend to evoke physiological, cognitive and emotional responses greater than neutral and positive events, (BAUMEISTER; BRATSLAVSKY; FINKENAUER, 2001; LYUBOMIRSKY, 2011), it is not known whether these results are the same when you evaluate consumer situations in which negative surprises occur. We expected that, in the face of a surprise with a strong 
magnitude, the adaptive process tends to be faster (for negative surprise) or delayed (for positive surprise).

Conceptually, hedonic adaptation is the reduction in the affective intensity of the favorable and non-favorable circumstances, generating a change in the level of enjoyment during consumption (FREDERICK; LOEWENSTEIN, 1999). Hedonic adaptation is defined by Wang, Novemsky and Dhar (2009, p. 149) as a "attenuation of affective reactions arising from the ownership and from the continuous use of a given product". Research on the subject sought to understand the adjustment in relation to products and experiences (NELSON; MEYVIS, 2008) and to discover new mechanisms that will extend the well-being of individuals, such as going shopping with friends (NEVES; BREI, 2015), being in a good mood (BREI; MARQUES; TCHOLAKIAN, 2012), to mentally categorize products differently (AQUINO; BREI, 2013), breaking out of the routine and even give up a purchase temporarily to (QUOIDBACH; DUNN, 2013; DUNN; GILBERT; WILSON, 2011; WILSON; GILBERT; CENTERBAR; 2003).

The prediction of the hedonic adaptation is a situation common to all people and refers to how the individual imagines she/he will feel about a situation that has not yet occurred. When someone thinks about how well she/he would feel at any given moment in future times, such as winning a prize or buying a product, she/he is trying to predict her/his hedonic adaptation. In the context of consumption, the prediction of the hedonic adaptation is an estimate by the consumer regarding the pleasure that she/he will feel with the use or consumption of goods in the future (WANG; NOVEMSKY; DHAR, 2009).

One of the mechanisms recently examined in order to understand hedonic adaptation is the positive surprise (BAO; BOEHEM; LYUBOMIRSKY, 2012). Evidence shows that surprise, when positive, prolongs the adaptation of the individual's well-being in relation to products and purchase experiences (WILSON; GILBERT, 2008). This means that the existence of an unexpected event in the process, such as winning a gift, causes the pleasure related to the consumption of a product last longer. Previous research sought to understand the forecast of the adaptation on products and experiences (NELSON; MEYVIS, 2008; WANG; NOVEMSKY; DHAR, 2009), as well as discovering conditions that prolong the time of individual's well-being (DUNN; GILBERT, WILSON, 2011; SHELDON; LYUBORMIRSKY, 2012). For example, Bao, Boehem and Lyubomirsky (2012) learned that individuals who received unexpected positive feedback about their performance in a course took more time to adapt. This occurs because, when one is surprised by a situation that is not 
expected, it takes more time to process and understand the new information, causing adaptation to not take place so rapidly. After this conceptual discussion of surprise and of hedonic adaptation, next we propose a conceptual model and the research hypotheses.

\section{THEORETICAL FRAMEWORK AND HYPOTHESES}

Although previous research has sought to understand the forecast of the adaptation on products and experiences (NELSON; MEYVIS, 2008; WANG; NOVEMSKY; DHAR, 2009), using the positive surprise as a background (BAO; BOEHEM; LYUBOMIRSKY, 2012), how the negative surprise interacts with several repetitions of consumption over time was not identified in the literature.

We expected that the occurrence of negative surprise has a stronger effect than the effect caused by positive surprise on the prediction of the consumer's hedonic adaptation for two reasons. First, people tend to mispredict the time when one will enjoy their purchases (WANG; NOVEMSKY; DHAR, 2009), ignoring the occurrence of hedonic adaptation. Prediction error can be more complex, of greater magnitude, when there is a negative surprise, because consumers often have positive consumption expectations. Second, consumers often want to know how their choices will affect their well-being because these expectations tend to guide decisions the entire time (HOERGER et al., 2012). The experience of a negative surprise affects those predictions, since it is closely linked to feelings of dissatisfaction and to the individual's emotional connections (VANHAMME; SNELDERS, 2001). Therefore, negative surprises generate frustration and lead to an accelerated path to the next choice (BELK; GER; ASKEGARD, 2003), being more intense than positive surprises. Based on this analysis, the first assumption evaluates the effects of the intensity of the negative surprise:

$\mathrm{H}_{1}$ : Negative surprise ( $v s$. positive) has a stronger ( $v s$. weaker)influence on the prediction of the expected pleasure (i.e., hedonic adaptation).

The second hypothesis deals with the time factor interacting with the surprise. Studies have shown that errors in hedonic adaptation prediction are common (LOEWESTEIN; SCHKADE, 1999; WILSON; GILBERT, 2003). Through error when predicting their wellbeing, people imagine they will go through a slower hedonic adaptation than it actually will occur, leading their desire for new purchases to resurface more quickly (PEREZ-TRUGLIA, 2012). This mistake made when predicting a future situation interferes directly in the real experience, because there is an overestimate about the duration of well-being over time, even before one had gone through the experience. This error of hedonic forecasting does not occur because of mistaken beliefs about how long a product will last, but because of a failure to 
incorporate beliefs regarding adaptation in the moment of choice (WANG; NOVEMSKY; DHAR, 2009).

Kahneman and Frederick (2002) stated that individuals tend to build preferences based only on information that are displayed explicitly in the environment and ignore relevant information that are not present. According to Wang, Novemsky and Dhar (2009), this construction of biased preference is one of the reasons why people tend to fail in their beliefs about adaptation. Furthermore, Nelson and Meyvis (2009) proved that interruptions at the consumption moment influence hedonic experiences, in such a way as to "sever" the process and affecting individual's adaptation speed. Based on these arguments, the second assumption deals with the bias of the prediction speed of adaptation:

$\mathrm{H}_{2}$ : The occurrence of negative surprise ( $v s$. positive) leads the consumer to predict that their hedonic adaptation will occur more quickly (vs. more slowly) over time.

Frederick and Loewenstein (1999) showed that the hedonic adaptation is the adaptation to stimuli that are affectively relevant, whether psychological or physiological. In this study, we analyzed psychological processes of choice and consumption (of songs), because they are less researched and are part of the universe of decisions of most consumers. The physiological processes of adaptation are also studied. For example, Schkade and Kahneman (1998) showed how people who have become paraplegic and face their new limited condition reduce their well-being when they are vigilant and think about what occurred. Over time, individuals' attention turns back to daily activities that make up their routine, which reduces the negative impact of the event on the perception about their well-being.

The phenomenon that describes the immediate response of individuals to good and bad circumstances, and after some time the tendency of these same individuals of going back to their neutral state, is called the hedonic treadmill (BRICKMAN; CAMPBELL, 1971). That is, hedonic adaptation is a behavioral response to the environment, of temporary nature, in which bad situations (such as a negative surprise) have their impact diminished over time and good situations gradually become less enjoyable (HELSON, 1964). Thus, we propose that:

$\mathrm{H}_{3}$ : The occurrence of negative surprise has inverse influence to that in positive surprise in the consumer's hedonic adaptation.

Bao, Boehem and Lyubomirsky (2012) showed that, when one is positively surprised, the individual is able to "cheat" the process and prolong the period of hedonic adaptation. However, very often, surprises related to experiences and to consumer goods are responses to 
negative events. Based on Baumeister, Bratslavsky and Finkenauer (2001), it is known that good and bad events are asymmetric, generating consistent effects over time. That is, the event of a negative surprise ( $v s$. positive) would cause the fall in hedonic adaptation to become more apparent over time. Therefore, we believe that the experience of negative surprise in consumption accelerates the process that leads to adaptation:

$\mathrm{H}_{4}$ : The occurrence of negative surprise (vs. positive) causes the consumer's hedonic adaptation to occur more rapidly ( $v s$. slowly) over time.

Figure 1 presents the framework that inspired two experiments to test the four hypotheses. From the literature review on the subject, three covariates (age, gender and involvement with the product) were incorporated to correct strange effects.

Experiment 1

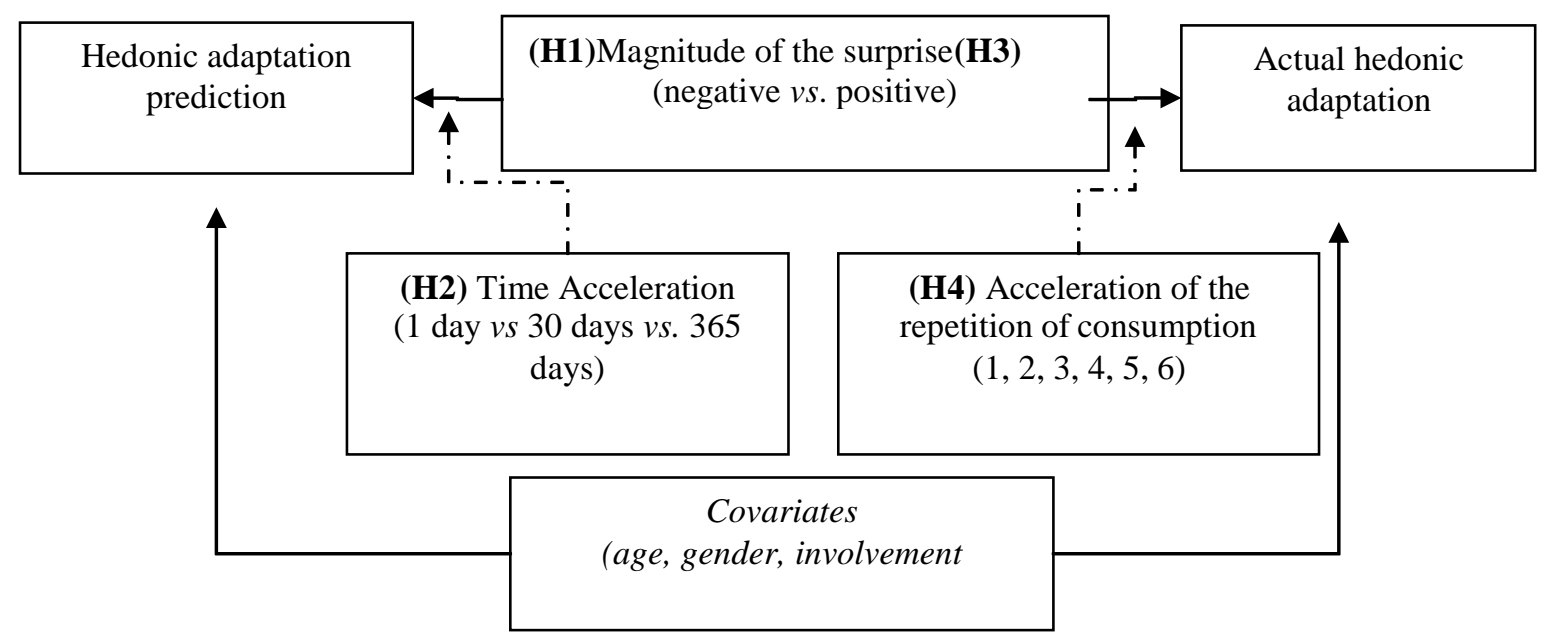

Figure 1 - Conceptual model proposing hedonic adaptation and time Source: Elaborated by the Authors.

\section{STUDY 1: PREDICTING HEDONIC ADAPTATION}

\subsection{STUDY DESIGN AND PROCEDURES}

We conducted Experiment 1 to test hypotheses $\mathrm{H}_{1}$ and $\mathrm{H}_{2}$, which analyze the magnitude and the speed of the effect of negative surprise on the hedonic adaptation prediction. Experiment 2 does not analyze the prediction, but the actual hedonic adaptation.

Design. Experiment 1 was a $2 \times 3$ mixed factorial design, so that surprise (positive, negative and neutral) was tested between-subjects. Time (1 day, 30 days, and 365 days) was tested within-subjects. Participants were recruited via Mechanical Turk (MTurk) from Amazon. This tool has been used in several recent studies published in leading social sciences journals (BOHANNON, 2011), marketing and consumer behavior journals (GALAK; 
KRUGER; LOEWENSTEIN, 2013). MTurk is a platform that allows the researcher to work with data from around the world and get accurate answers in short periods, for a moderate price (BOHANNON, 2011). Data collection occurs more quickly and it presents a high degree of reliability, due to the possible filters of qualification that may be used. In the case of this research, we used the filter that corresponds to respondents classified as "Master"- Workers with a high number of responses (usually above 10.000) and quality in responses previously attested by applicants from previous researches. Workers who corresponded to this requirement were enabled to respond to the survey through the system and received $\$ 0.30$ for each task completed, an average price for experiments with similar duration and complexity.

Procedures. Participants of the three surprise groups (positive, negative and neutral) had access to the same image and similar information (Figure 2). Next, they were exposed to different scenarios that manipulated the independent variable "surprise" during situations of consumption of a digital camera. Users from the negative surprise group visualized a message that requested them to imagine that they had bought that digital camera model recently and, after some days of use, they discovered that the camera had been voted as the worst one of its category in 2013. As for the participants of the positive surprise group, they visualized a message that required them to imagine the same purchase, but that they had discovered, after some days of use, that the camera was voted best of its category in 2013. Users of the control group received a message requesting them to imagine buying a camera and its normal usage. The image of the camera did not have any brand or model to avoid confound effects. 


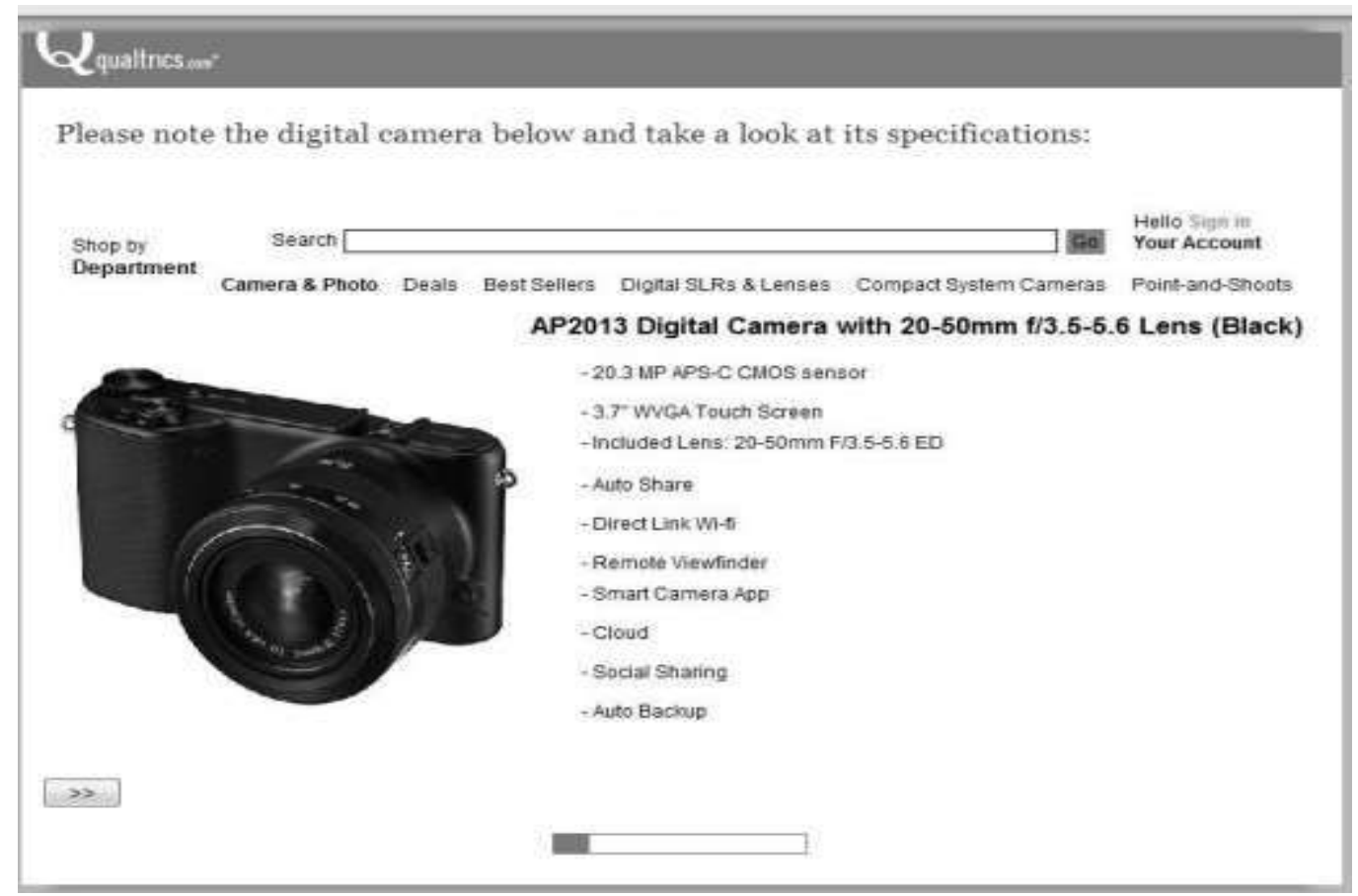

Figure 2 - Initial scenario example used in Study 1

Source: Elaborated by the authors.

The participants of the three groups responded to the same questions about hedonic adaptation prediction (independent variable), adapted from Wang, Novemsky and Dhar (2009): "How enjoyable do you think it will be to use this digital camera in 1 day?" (vs. in 30 days days $v s$. in 1 year), varying from $1=$ not at all, to $9=$ very much, from the moment they became aware of the surprise or not.

Covariates. Age, gender, and involvement were measured as covariates. The participants filled out Zaichkowsky's (1985) involvement scale. This 7-point scale was used to measure the degree of involvement of participants in relation to the product used in Study 1 (digital camera). Involvement relates to the perceived importance of a product based on values, interests, and needs of the consumer.

Manipulation check. In the final stage of the experiment, the participants filled out a semantic differential scale to check how surprised they felt upon learning about the classification of the camera. The scale ranged from negatively surprised $=-4$ to positively surprised $=+4$, as suggested by Godwin (2010), followed by a debriefing question to evaluate whether the subjects suspected the research goal.

\subsection{RESULTS}

Sample. One hundred and twenty participants were divided into three scenarios. The final sample was composed of 110 individuals ( 65 women and 45 men; $47.3 \%$ aged between 
21 and 30 years of age; 91.8\% residents of the United States of America). The prevailing annual income of the participants (25.5\% of the sample) was $\$ 60.000$ or more.

Manipulation check. We supported the manipulation check of the surprise stimulus. The control group had lower average than the positive surprise one (Kruskal-Wallis KW = 23.84; $p<0.001)$ and greater than the negative surprise $(\mathrm{KW}=32.89 ; p<0.001)$. The positive surprise group had average noticeably greater than the negative surprise one $(\mathrm{KW}=-56.63$; $p<0.001)$.

Examination of the main effects. The results showed that the involvement covariates $(F(1.109)=2.00 ; p<0.165)$, gender $(F(1.109)=0.80 ; p<0.37)$ and age $(F(1.109)=0.07 ; p<0.78)$ did not have significant effects in the prediction of adaptation. However, the effect of time on hedonic adaptation happened as expected $(F(1.109)=6.43 ; p<0.02)$. Based on this effect, we carried out a comparison of groups via post-hoc test (Scheffe's test). The findings showed that the mean of the hedonic adaptation prediction in period 1 was $M=6.78$, decreasing in period two of 30 days; $\left(M_{30}\right.$ days $\left.=6.08 ; p<0.001 ; F=4.92 ; p<0.02\right)$, and decreasing further in period three of 365 days $\left(M_{365}\right.$ days $\left.=5.13 ; p<0.001 ; F=7.24 ; p<0.02\right)$. As expected, we observed an effect of the priming of time elapsed on the expected pleasure. In other words, people imagined that they would have less pleasure with the product at different moments in the future, highlighting the main effect of hedonic adaptation prediction.

Hypotheses Testing. The first hypothesis tested the impact of the intensity of the negative surprise on the adaptation forecast. The magnitude of the negative surprise was expected to be more intense than the positive $\left(\mathrm{H}_{1}\right)$. We estimated an equation where surprise was the independent variable, hedonic adaptation prediction (calculated as an average of the three periods $(\alpha=0.88)$ ) was the dependent variable, and involvement, gender, and age were covariates. The results showed that the involvement had a significant effect on hedonic adaptation prediction $(F(1.109)=8.16 ; p<0.005)$, but gender $(F(1.109)=1.12 ; p<0.29)$ and age did not effect it $(F(1.109)=0.07 ; p<0.79)$.

The effect of surprise on hedonic adaptation prediction was significant $\left(F(1.109)=76.72 ; p<0.001 ; \eta^{2}=0.56\right)$. The results, corrected after the covariate effects, showed that the averages of hedonic adaptation prediction were: negative surprise $M=3.64$, being lower than the control's group average $M=6.74(p<0.001)$, which was lower than the positive surprise group average $M=7.65$ ( $p<0.001$ ). It is worth pointing out that the magnitude of the negative surprise was examined by the comparison of two ANOVAs, comparing them to the neutral point. The magnitude was measured by the beta - angular coefficient of the 
straight line. The magnitude of the positive surprise had significant effect size $(F(1.73)=9.66$; $\left.p<0.003 ; \beta=0.84 ; \eta^{2}=0.29\right)$, although much weaker than the negative surprise $\left(F(1.73)=64.79 ; p<0.001 ; \beta=-3,02 ; \eta^{2}=0.48\right)$, supporting the first hypothesis about the intensity. Therefore, the magnitude of the negative surprise on the hedonic adaptation prediction was significant, supporting hypothesis $H_{l}$.

Considering that hedonic adaptation prediction as the dependent variable was estimated using the average of the three periods, it can be biased by the different manipulation conditions, because the averages do not show separately the magnitude at each moment in time. Thus, three ANOVAs were carried out for each period to measure the intensity of adaptation in each condition. This is a second way to test hypothesis $\mathrm{H}_{1}$. On the one-day condition, the effect of the negative surprise on the hedonic adaptation prediction was significant $\left(F(1.109)=37.23 ; p<.001 ; \eta^{2}=0.10 ; M_{\text {Negative surprise }}=4.65 v s . M_{\text {Positive surprise }}=8.17\right)$. Over the 30 days condition, the intensity of the negative surprise on the hedonic adaptation prediction was again significant $\left(F(1.109)=61.47 ; p<0.001 ; \eta^{2}=0.54 ; M_{\text {Negative surprise }}=3.66 v s\right.$. $\left.M_{\text {Positive surprise }}=7.70\right)$. Finally, on the 365 days condition, the magnitude of the negative surprise on the hedonic adaptation prediction was also significant $(F(1.109)=54.54 ; p<0.001$; $\eta^{2}=0.51 ; M_{\text {Negative surprise }}=2.61 \mathrm{vs} . M$ Positive surprise $=7.08$ ). In summarize, the intensity of the negative surprise on the hedonic adaptation prediction was significant in all three conditions, demonstrating strong evidences to support $\mathrm{H}_{1}$.

Next hypothesis $\mathrm{H}_{2}$ was tested. We expected that the negative surprise (vs. positive) would cause a stronger decline in the hedonic adaptation as time goes by. GreenhouseGeisser's test showed a significant result $(F(1.109)=3.72 ; p<0.04)$, showing that there is interactive effect between different time periods and the surprise, leading to the support of $H_{2}$. As shown in Figure 3, as time goes by, the levels of pleasure with consumption predicted fall, stressing that adaptation is an inevitable process in consumption situations (WANG; NOVEMSKY; DHAR, 2009; GALAK; KRUGER; LOEWENSTEIN; SCHKADE, 1999). However, the decline in the level of pleasure is stronger when negative surprise occurs ( $v s$. positive). Therefore, the averages show that the negative surprise ( $v s$. positive) caused a stronger ( $v s$. weak) hedonic adaptation prediction, supporting $\mathrm{H}_{2}$. 


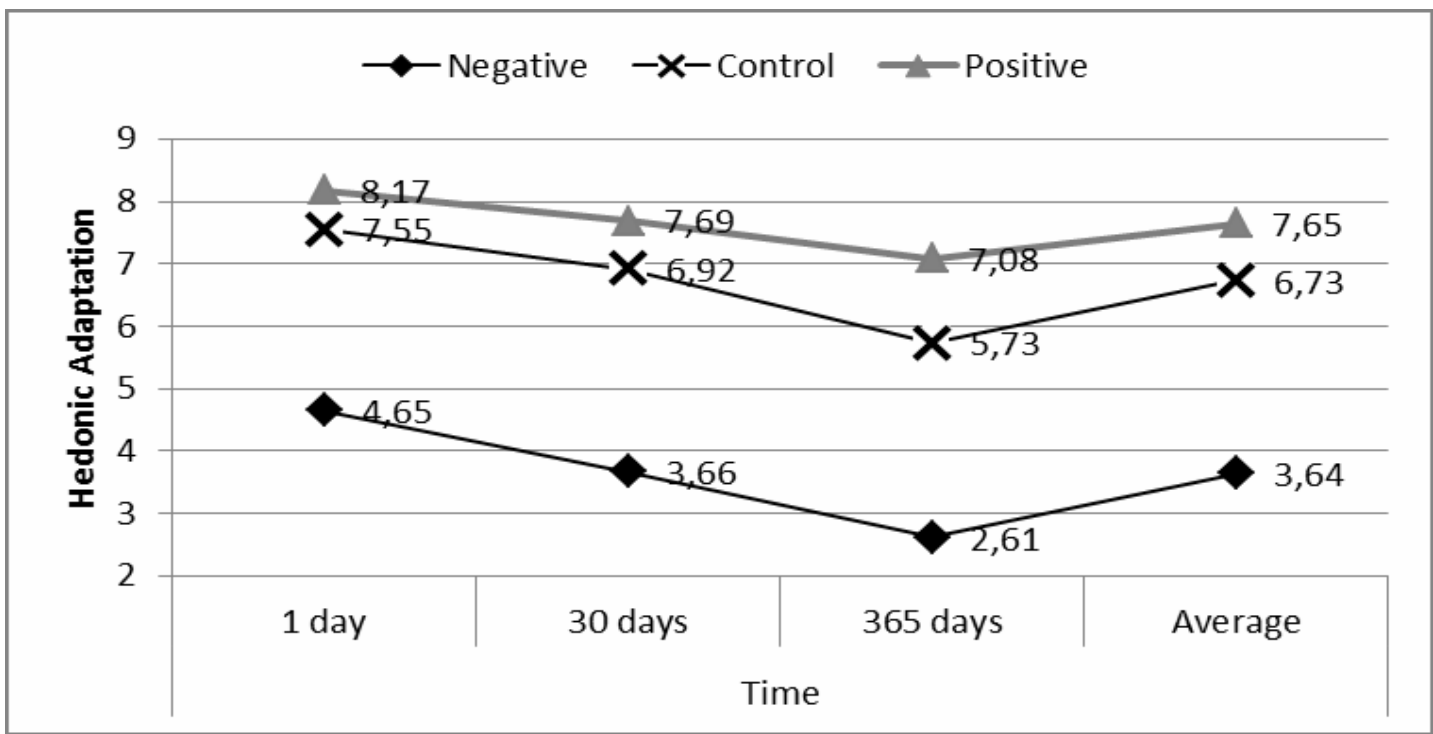

Figure 3 - Time interaction $\times$ surprise on predicitons of adaptation Source: Elaborated by the authors.

\subsection{DISCUSSION OF STUDY 1}

$\mathrm{H}_{1}$ suggested that the negative surprise has a stronger effect on hedonic adaptation. Results showed that the negative surprise brings a lower expectation of future pleasure with consumption, in contrast to the positive surprise, which leaded individuals to imagine that they will have greater future pleasure with the purchase.

However, the intensity of the negative surprise is greater $(\beta$ negative surprise $=-3.02 \mathrm{vs}$. $\left.\beta_{\text {positive surprise }}=0.84 ; \Delta=3.86\right)$. Participants that faced the negative surprise estimated the adaptation greater magnitude in all time moments, when compared to other groups. However, the velocity of the pleasure decline was similar between the groups.

Hypothesis $\mathrm{H}_{2}$ tested the possibility of the consumer to forecast hedonic adaptation more rapidly before the occurrence of the negative surprise. The two levels (positive and negative) of surprise were estimated in the ANOVA equation, and the hypothesis $\mathrm{H}_{2}$ was supported. We observed that, as time goes by, the forecasted enjoyment (i.e., hedonic adaptation) with the product decreased, but there was a greater fall in pleasure with the negative surprise, leading us to some important conclusions. First, this result is consistent with the theory that says that the usefulness (i.e. utility) of a product decreases over time due to the fall of the related novelty and the change in perspective or expectations (WANG; NOVEMSKY; DHAR, 2009). Second, these findings are aligned with Baumeister, Bratslavsky and Finkenauer (2001), who claim that bad emotions have greater impact than good emotions, generating more severe consequences that last longer. Third, the results are also in agreement with Lyubormirky (2011), who pointed out that the negative domain is related to the activation and with the acceleration of hedonic adaptation, and individuals who 
have suffered negative experiences felt the impact when they happen, never recovering completely.

\section{STUDY 2: LIVING THE HEDONIC ADAPTATION}

\subsection{STUDY DESIGN AND PROCEDURES}

Design. Study 2 was a $3 \times 6$ factorial design. Surprise (positive, negative, and neutral) was manipulated between-subjects and repetitions (six repetitions of consumption) manipulated within-subjects. A sample of 91 students of undergraduate courses was recruited among the students of a large Brazilian University. In the beginning of the experiment, the participants were directed to a computer lab with one computer for each person, with access to the internet and headphones. They were informed that they would participate in a consumption simulation to buying a video clip over the internet, similar to previous consumer behavior research (NICOLAO; IRWIN; GOODMAN, 2009). The video clip shopping was chosen due to the importance of this market. Apple's iTunes Store alone earned $\$ 4.7$ billion with music videos in 2013 (CANALTECH, 2014).

Procedures. The participants accessed an online store specialized in music videos, created specifically for this research, The Music Shop (Figure 4), that was inspired on the bestselling video website in the world, iTunes Store. We decided to create a website to avoid involvement effects resulting from existing website. Each participant received a credit of $\mathrm{R} \$$ 1.00 to purchase a music video, to be chosen from the Billboard top ten ranking positions at the time of completion of the study. All videos had their duration reduced to a minute each, to avoid effects of different lengths, which could influence on indexes of adaptation after exposure to repetitions. Once the preferred video clip was chosen, the participants of the three groups watched the video for the first time. After that, they were required to respond to the measuring scale of hedonic adaptation: "How pleasurable was to watch this music video now?", with 1 = not at all pleasurable and 9 = very pleasurable (WANG; NOVEMSKY; DHAR, 1999).

After answering to the scale, participants clicked on a link that directed them to watch the music video purchased once again. Thus, the participants went through a sequence of six video replays in total (repetitions were the priming that stimulated the occurrence of hedonic adaptation), always filling the scale of adjustment after each execution of the video. 


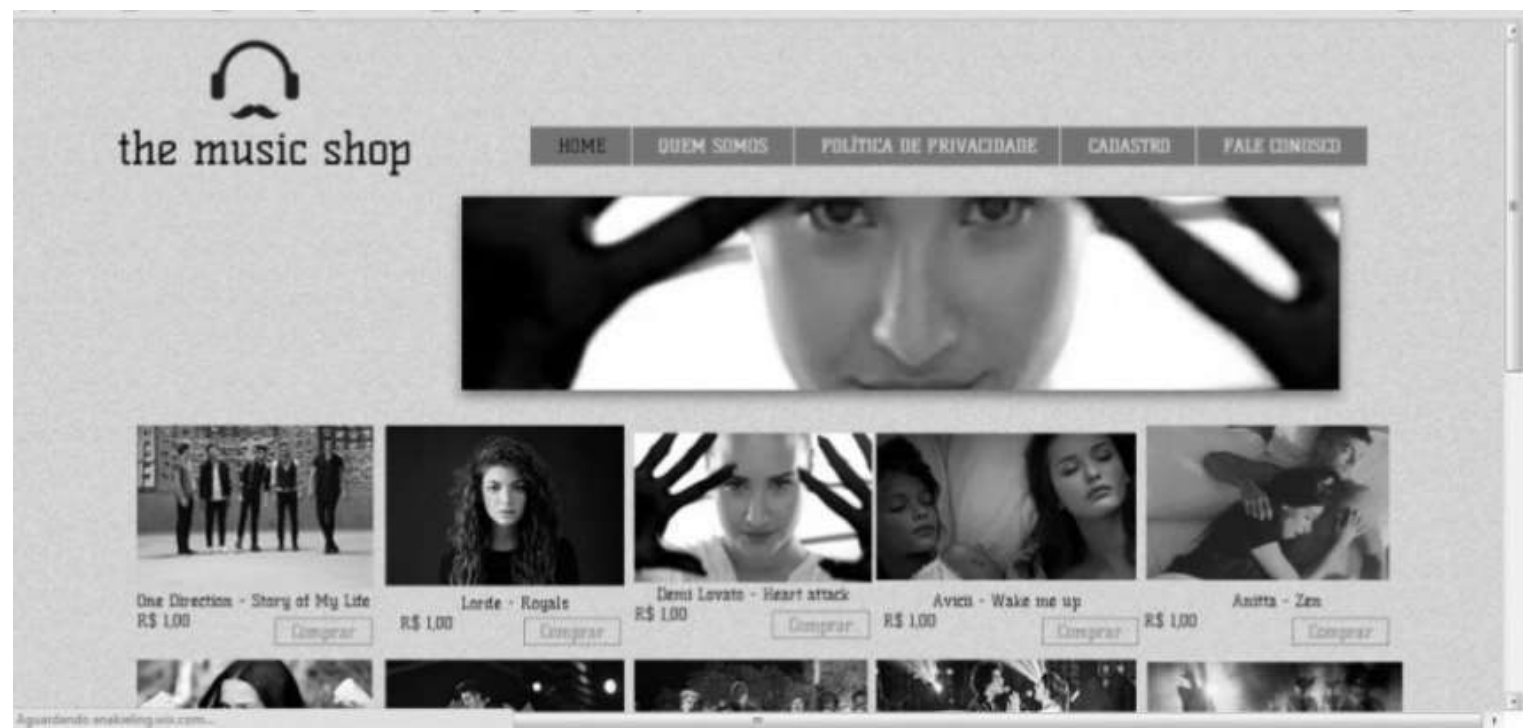

Figure 4 - Initial screen of the online store used in Study 2 Source: Elaborated by the authors.

Manipulation. Manipulation was done by means of a simulation of video consumption with one insertion of a specific surprise (positive or negative), in the middle of the consumption process (i.e., watching the video clip). That surprise was an unexpected situation in product use, evidenced during use, which sought to unleash a surprise. The occurrence of the surprise (manipulated group) or not (control group) during the consumption process aimed to check its effect on the magnitude and speed of consumer's actual hedonic adaptation.

The surprise manipulation occurred during the third repetition. The negative surprise group experienced a problematic situation when playing the video (Figure 5). The manipulation was in the music video itself, which featured a visual glitch added to an annoying noise for five seconds, starting from the $26^{\text {th }}$ second of the video. In the positive surprise manipulation, we showed a message during the third exhibition of the video: "We noticed that you really like this music video! You just won a set of exclusive information on its production, sent to your email". The positive surprise group received subsequently to the experiment, an e-mail with this information. The control group performed the video normally in all repetitions, without any interruption. 


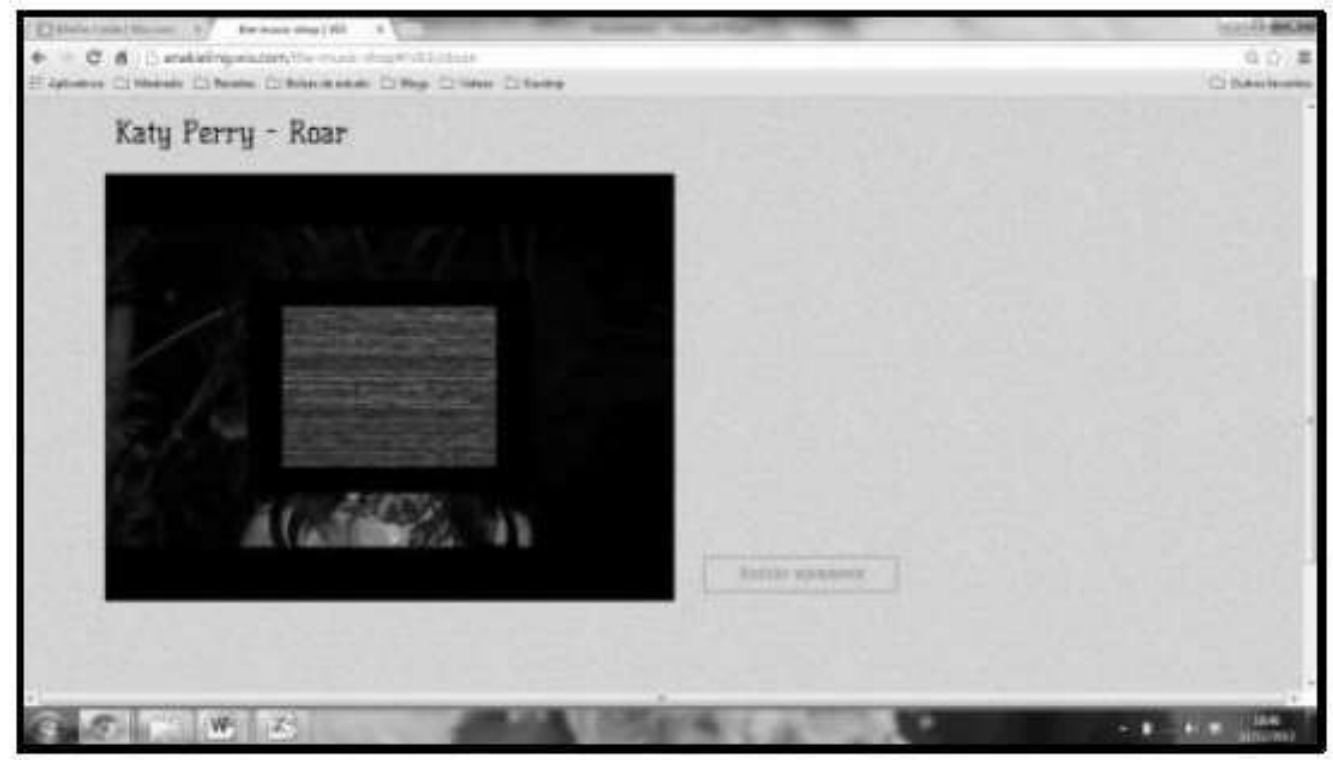

Figure 5 - Negative Surprise stimulus in the $3^{\text {rd }}$ repetition Source: Elaborated by the authors.

In the end of the six exhibitions of the video, all participants filled out a semantic differential scale, being $-4=$ negatively surprised and $+4=$ positively surprised, to measure how surprised they felt when unexpected events occurred in the purchased video. This scale was used for the manipulation check. In the end, we asked a debriefing question to evaluate whether the subjects suspected about the research goals.

\subsection{RESULTS}

Sample. 95 undergraduate students were divided into three groups. The final sample was composed of 91 people (50 women and 41 men; 71.4\% aged between 21-30 years of age). Participants were randomly allocated in each of the three groups.

Manipulation check. The manipulation check of the surprise stimulus was supported, and data showed that there were significant differences, as expected. The control group had lower average pleasure compared to the positive surprise group $(\mathrm{KW}=-17.90 ; p<0.008)$. The control group had greater average than the negative surprise group $(\mathrm{KW}=24.41 ; p<0.001)$, and the positive surprise group had greater average than the negative surprise group $(\mathrm{KW}=-$ 42.31; $p<0.001)$.

Main Effect. To verify the hypothesis, we used a General Linear Model (GLM) of repeated measures; a variation of the ANOVA family. Time was manipulated within-subjects, that is, each person watched the music video six times during the experiment. The withinsubject test showed no significant difference in time $(F(5.60)=1.31 ; p<0.27$; GreenhouseGeisser). The results showed that the covariates genre $(F(1.55)=0.29 ; p<0.59)$ and age 
$(F(1.55)=.03 ; p<0.86)$ had no significant effect on hedonic adaptation. Involvement did have an impact on hedonic adaptation $(F(1.55)=5.82 ; p<0.02)$.

Test of hypotheses. We expected that the magnitude of the negative surprise to be more prominent than the intensity of the positive surprise on hedonic adaptation $\left(\mathrm{H}_{3}\right)$. First, in order to examine this hypothesis, we did an analysis of repeated measures with the three surprise groups. Surprise did not have the expected effect on hedonic adaptation, because there was no significant differences between the groups $(F(2.85)=0.46 ; p<0.62)$.

Second, to examine the hypothesis $\mathrm{H}_{3}$, we compared the repeated measures of the two surprise groups (positive and negative). The surprise had no influence on the hedonic adaptation as expected, because there was no significant difference between the groups $\left(F(1.55)=0.57 ; p<0.45 ; M_{\text {positive }}=5.75\right.$ vs. $\left.M_{\text {negative }}=5.40\right)$, which led to the rejection of hypothesis $H_{3}$.

The last hypothesis $\left(\mathrm{H}_{4}\right)$ evaluated the effect of the interaction time $\times$ surprise on hedonic adaptation. We expected that the event of negative surprise ( $v s$. positive) would cause the fall on hedonic adaptation to be more pronounced over time. To examine this hypothesis, we did an analysis of repeated measures with the two surprise groups (positive and negative). The result was significant $\left(F(5.55)=5.14 ; p=0.01 ; \eta^{2}=0.085\right.$; Greenhouse-Geisser's test, contrast repeated) and, therefore, hypothesis $\mathrm{H}_{4}$ was supported. The difference in contrast was found between level $2 v s$. level $3(F(1.55)=23.85 ; p<0.001)$, between level 4 vs. level 3 $(F(1.55)=4.03 ; p<0.05)$ and between level 4 vs. level $5(F(1.55)=5.57 ; p<0.02)$. Figure 6 shows the averages.

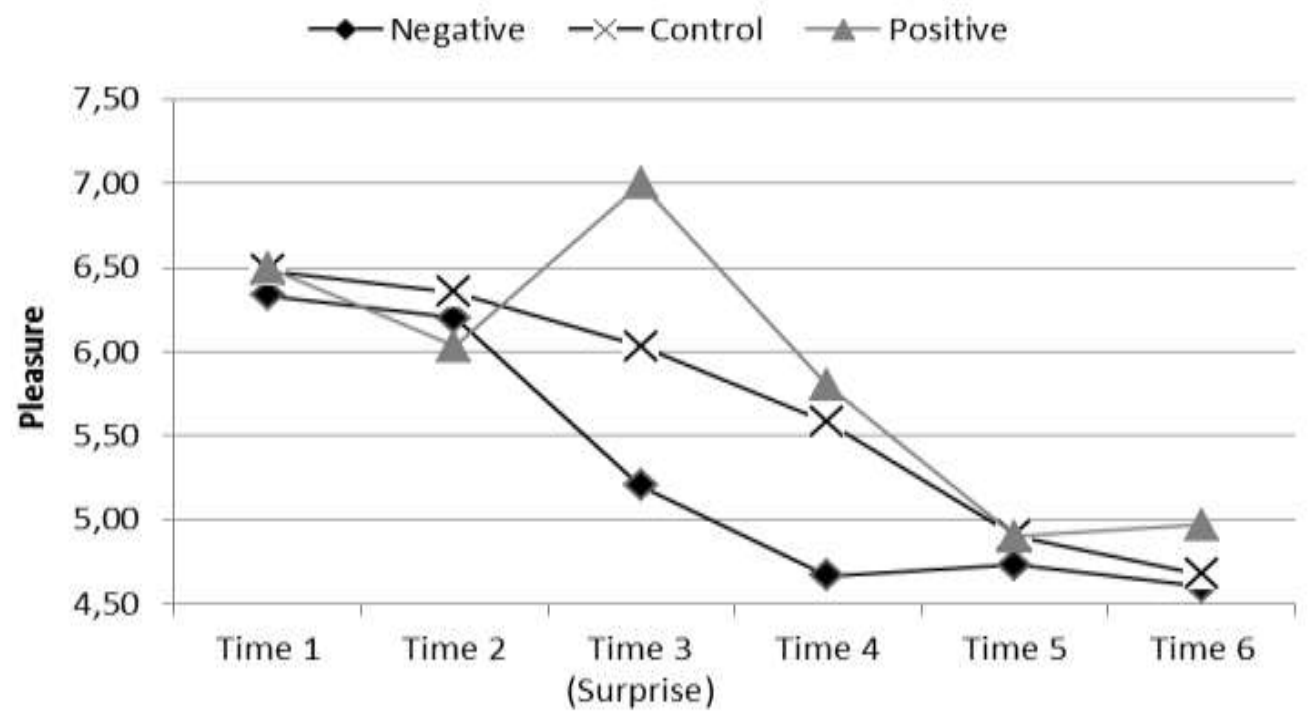

Figure 6 - Interaction surprise $\times$ Repetitions Source: Elaborated by the authors. 
Results show that the averages of the negative surprise group decreased from the first to the sixth repetition. As expected, this fall intensified from the third to the fourth repetition, when the negative surprise manipulation occurred within the video. The average pleasure of the positive surprise group also dropped, but there was a peak in the third repetition, when the manipulation occurred. A pos hoc analysis showed that, before the third repetition, there was only a main effect of time on hedonic adaptation $(F=5.40 ; p<0.02)$. However, after the third repetition, there was an interactive effect time $\times$ surprise $(F=2.69 ; p<0.04)$.

After checking the interaction effect, we tested the effect of surprise on repetitions 3, 4 and 5, after surprise manipulation. The covariates involvement, gender and the three repetitions $(F(1.87)=0.06 ; p<0.81)$ did not impact adaptation significantly. However, the time $\times$ surprise interaction not only evidenced a linear effect $(F(1.87)=2.48 ; p<0.08)$, but it also presented a U-shaped effect $(F(1.87)=3.35 ; p<0.04)$. This U-shaped curvilinear effect was detected because, after exposing subjects to the positive surprise (vs. negative) manipulation, there was an increase ( $v s$. decrease) in pleasure differently in relation to other moments. Interestingly, in the latest time intervals (levels 5 and 6), adaptation occurred again in magnitude similar to the moments prior to the surprise.

\subsection{DISCUSSION OF STUDY 2}

The effect of the surprise's magnitude on the hedonic adaptation process was not observed in Study 2. We believed that the magnitude of the negative surprise would influence the adaptation in a more prominent way than the positive surprise, leading therefore, to the rejection $\mathrm{H}_{3}$. A possible explanation may be regarding the duration of the negative manipulation during the video exhibition that may have been small in order to generate a strong negative surprise.

Hypothesis $\mathrm{H}_{4}$ tested if hedonic adaptation would occur more rapidly before the experience of a negative surprise in a consumption situation, causing an acceleration of the fall in pleasure over time. We supported the result because we observed that adaptation increased (i.e., pleasure decreased) as the repetitions were played, but there was a greater fall in pleasure after the occurrence of the negative surprise. Research on positive psychology (LYUBOMIRSKY, 2011) shows that people who experience positive surprises and new experiences feel happier for longer periods of time, a phenomenon also observed in this research. We have found that, first, the positive surprise presents a quadratic effect, that starts with a strong elevation of pleasure with the consumption, followed by a strong fall. Second, the negative surprise accelerates the process of hedonic adaptation, reducing the pleasure of 
consumption. Based on these evidences, individuals of the group exposed to the negative surprise experienced a more accelerated decrease of pleasure with respect to the purchased music video compared to control and positive surprise groups. More specifically, consumers experienced a peak of pleasure ( $v s$. displeasure) shortly after viewing the video that had a positive surprise ( $v s$. negative). After the manipulation, the group exposed to the negative surprise showed a sharp decline in pleasure in the following repetitions, which drove to increasingly lower levels compared to other groups.

\section{CONCLUSIONS}

Studies that addressed the role of surprise are not new in marketing and consumer behavior literature (VANHAMME, 2000). However, research about the influence of negative surprise in the consumer's forecast and actual hedonic adaptation were not identified in literature and suggest a gap for studies. Given this space, we proposed a conceptual framework to test the effects of the different types of surprises. The tested the hypothesis with two experiments, using the procedures and the protocols recommended by Galak, Kruger and Loewenstein (2013) and Wang, Novemsky and Dhar, (2009).

Our experiments demonstrate three relevant findings for consumer behavior literature. First, we show that individuals predict a decrease in pleasure more accelerated in time when faced with a negative surprise, when compared to other situations (neutral or positive surprises). This effect might cause acceleration in consumption, which in macroeconomic terms, may appear as a satisfactory result for the industry and for the economy in general. However, the conclusion that a negative surprise affects the consumer's hedonic adaptation prediction in a harmful way - in the short and long term - may have important implications on post-consumer processes, notably with regard to the consumer's satisfaction and loyalty, as well as brand management. Negative surprises can make consumers imagine that they will have less pleasure out of the product purchased in the future. This process tends to reduce the satisfaction and loyalty of consumers, possibly speeding up the exchange process of the purchased product, making room for competitors. Brands involved with the negative surprise tend to suffer losses in their image, and the negative value in surprise generates dissatisfaction, which drives to negative word-of-mouth (DERBAIX; VANHAMME, 2003).

Second, the levels of pleasure of the three groups had significant differences, and the negative surprise influenced individuals to feel adapted to the product more quickly when compared to other groups. Therefore, there is interaction effect from time $\times$ surprise on the hedonic adaptation. Participants of the positive surprise group experienced a peak of pleasure 
after being exposed to the stimulus, but followed by a decrease in pleasure just as the others. This rapid change of direction can be attributed to the fact that the effects of positive events dissipate more easily than that of negative events (BAUMEISTER; BRATSLAVSKY; FINKENAUER, 2001). Nevertheless, this research complements the literature on positive surprise (BAO, BOEHEM; LYUBOMIRSKY 2012; DUNN, WILSON; GILBERT 2011). These studies showed that the positive surprise is able to "cheat" adaptation, leading consumers to feel happier for a longer time with their purchases. These studies still show that negative also accelerate psychological phenomena associated with pleasure with consumption.

Third, the discovery that the negative surprise influences the prediction and the actual hedonic adaptation, causing individuals to have their pleasure reduced when consuming products and experiences, can bring out important consequences. If the acceleration of consumption appears to be evident, probably reducing the life cycle of products, complaints of consumers also tend to increase. As ways to check the qualifications of products and services offered on the market arise - such as complaints websites (e.g.: Reclame aqui) and services assessments portals (e.g.: Trip advisor) -, companies' shortcomings that generate negative surprises tend to bring substantial loss in brand image and sales. Stead (2012) showed that negative reviews have immediate impact on consumers' decisions, affecting more than the positive reviews.

Future research and limitations. Even though the findings from the two experiments are consistent in the sense of highlighting the concern with the effects of surprise in the consumer adaptation process, future studies that explore some unanswered gaps. For example, researches that longitudinally analyze hedonic adaptation will bring more external validity to the usual laboratory studies. Second, we suggest an expansion on the studies about the effects of surprise, regardless of the value, on the consumer adaptation processes - especially adaptation and satiation. Third, in addition to interruption (important for the advertisement industry), phenomena related to behavioral aspects can also be analyzed (for instance: effects of surprise in consumer memory), as well as physiological aspects (for example: changes in breathing or an increase in bodily conductivity), verbal/subjective (for instance: spontaneous vocalization).

The possibility of the influence of type of the tested product and service on consumers' behaviors is a limitation of this research. Thus, future studies should compare whether the 
type of product and service (for example: innovative or traditional) accelerates even further or whether it reduces consumer's hedonic adaptation, given the different levels of surprise.

To maintain a panel sample for one year is something. In the case of Study 1, a panel sample would avoid the need of forecasting measures and provide real data of adaptation in a day, a month and a year, in order to check whether the predictions of individuals were correct or not. Moreover, both studies restricted the research to products and to scenarios of specific purchases. It is possible that different products and services may be able to strengthen the results we found. We also suggest an extension of the results of this paper analyzing postpurchase behavior and the consumer relationship with the product and with the brand after experiencing an unexpected and unpleasant consumption situation.

\section{THANKS}

This research was partially financed with funds from the Universal Notice CNPq Universal 14/2013, Project 481642 / 2013-7.

\section{REFERENCES}

A NO, L. S.; BRE, V. A. poss vel manter nosso bem-estar consumindo a mesma variedade de produtos? A influ ncia da categori a o na sacia o do consumidor. , v. 24, n. 1, p. 16-27, 2013.

BAGOZZI, P.; GOPINATH, M.; NYER, U. The role of emotions in marketing. Journal of the Academy of Marketing Science, v. 27, n. 2, p. 184-206, 1999.

BAO, K. J.; BOEHM, J. K.; LYUBOMIRSKY, S. Using surprise to stay happier: thwarting hedonic adaptation to positive events. 2012. Disponível em:

=http://sonjalyubomirsky.com/papers-publications/>. Acesso em: 11 jan. 2015.

BAUMEISTER, R. F.; BRATSLAVSKY, E.; FINKENAUER, C. Bad is stronger than good. Review of General Psychology, v. 5, n. 4, p. 323-370, 2001.

BELK, R.; GER, G.; ASKEGARD, S. The Fire of Desire: a multisided inquiry into consumer passion. Journal of Consumer Research, v. 30, n. 3, p.326-351, 2003.

BOHANNON, J. Social science for pennies. Science, v. 334, n. 6054, p. 307, 2011.

BREI, V. A.; MARQUES, T. R. F.; TCHOLAKIAN, N. Bom humor é bom para consumir menos? Uma análise das relações entre humor e saciação de consumo. Análise (PUCRS), v. 23, n. 2, p. 118-128, 2012.

BRICKMAN, P.; CAMPBELL, D. T. Hedonic relativism and planning the good society. In: APLEY, M. H. Adaptation-level theory: a symposium. New York: Academic Press, 1971. p. 287-302. 
CANALTECH. Apple registra faturamento recorde no final de 2013. 2014. Disponível em: <http://corporate.canaltech.com.br/noticia/apple/Apple-registra-faturamento-recorde-nofinal-de-2013/>. Acesso em: 18 abr. 2015.

DERBAIX, M.; VANHAMME, J. Inducing word-of-mouth by eliciting surprise: a pilot investigation. Journal of Economic Psychology, v. 24, n.1, p. 99-116, 2003.

DIENER, E.; LUCAS, R. E.; SCOLLON, C. N. Beyond the hedonic treadmill: revising the adaptation theory of wellbeing. American Psychologist, v. 61, n. 4, p. 305-314, 2006.

D NN, E.; G LBERT, D.; W LSON, T. f money doesn't make you happy, then you probably aren't spending it right. Journal of Consumer Psychology, v. 21, n.2, p. 115-125, 2011.

FREDERICK, S.; LOEWENSTEIN, G. Hedonic Adaptation. In: KAHNEMAN et al. Wellbeing: the foundations of hedonic psychology. New York, NY: Russell Sage Foundation. p. 302-329, 1999.

GALAK, J.; KRUGER, J.; LOEWENSTEIN, G. Slow down! Insensitivity to rate of consumption leads to avoidable satiation. Journal of Consumer Research, v. 39 n. 5, p. 993 1009, 2013.

HELSON, H. Adaptation-level theory: an experimental and systematic approach to behavior. New York: Harper and Row, 1964. 732 p.

HOERGER, M. et al. Emotional intelligence: a theoretical framework for individual differences in affective forecasting. Emotion, v, 12, n.4, p.716-725, 2012.

KAHNEMAN, D.; FREDERICK, S. W. A model of heuristic judgment. In: GILOVICH et al. Heuristics of intuitive judgment. New York, NY: Cambridge University Press, 2002.

LOEWENSTE N, G. F.; SCHKADE, D. Wouldn't be nice? Predicting future feelings. n: KAHNEMAN et al. Well-being: the foundations of hedonic psychology. New York: Russel Sage Foundation, 1999. p. 88-105.

LYUBOMIRSKY, S. Hedonic adaptation to positive and negative experiences. In: S. FOLKMAN, S. Oxford Handbook of stress, health, and coping. New York: Oxford University Press, 2011.

MELLERS, B.; RITOV, I.; SCHWARTZ, A. Emotion-based choice. Journal of Experimental Psychology: General, v.128, n.3, p. 332-345, 1999.

NELSON, L. D.; MEYVIS, T. Interrupted consumption: disrupting adaptation to hedonic experiences. Journal of Marketing Research, v.45, n.6, p. 654-664, 2008.

NEVES, G.; BREI, V. O impacto da interação social na adaptação hedônica do consumidor. Revista de Administração Contemporânea, (No prelo).

NICOLAO, L., IRWIN, J. R.; GOODMAN, J. K. Happiness for sale: do experiential purchases make consumers happier than material purchases? Journal of Consumer Research, v. 36, n. 2, p. 188-198, 2009. 
PEREZ-TRUGLIA, R. On the causes and consequences of hedonic adaptation. Journal of Economic Psychology, v. 33, n.6, p. 1182-1192, 2012.

QUOIDBACH, J. DUNN, E. W. Give it up: a strategy for combating hedonic adaptation. Social Psychological and Personality Science, v.4, n.5, p. 1-6, 2013.

SCHKADE, D. A.; KAHNEMAN, D. Does living in California make people happy? A focusing illusion in judgments of life satisfaction. Psychological Science, v. 9, n. 5, p. 340346, 1998.

SHELDON, K. M.; LYUBOMIRSKY, S. The challenge of staying happier: testing the hedonic adaptation prevention model. Personality and Social Psychology Bulletin, v. 38, n. 5, p. 670-680, 2012.

STEAD, L. How do consumer reviews on TripAdvisor affect consumer decision making when booking an international hotel. Hospitality Management Review Student Journal, v. 2, 2012. Disponível em: 〈http://research.shu.ac.uk/domino/index.php/HMJ/article/view/21〉. Acesso em: 11 jan, 2015.

TAYLOR, S. Asymmetrical effects of positive and negative events: the mobilizationminimization hypothesis. Psychological Bulletin, v. 110, n. 1, p. 67-85, 1991.

VANHAMME, J.; SNELDERS, D. The role of surprise in satisfaction judgements. Journal of Consumer Satisfaction, Dissatisfaction and Complaining Behavior, v. 14, p. 27-45, 2001.

VANHAMME, J. The link between surprise and satisfaction: an exploratory research on how best to measure surprise. Journal of Marketing Management, v.16, n.6, p. 565-582, 2000.

WANG, J.; NOVEMSKY, N.; DHAR, R. Anticipating adaptation to products. Journal of Consumer Research, v. 36, n. 2, p. 149-159, 2009.

WATKINS, M. D.; BAZERMAN, M. H. Predictable surprises: the disasters you should have seen coming. Harvard Business Review, v. 81, n.3, p. 72-85, 2003.

WILSON, T. D.; GILBERT, D.T. Affective forecasting. Advances in Experimental Social Psychology, v.35, p. 345-411, 2003.

WILSON, T. D.; GILBERT, D.T.; CENTERBAR, D. B. Making sense: the causes of emotional evanescence. The psychology of economic decisions. Rationality and well-being, v.1, p. 209 -233. New York: Oxford University Press, 2003.

WILSON, T. D.; GILBERT, D.T. Explaining away: a model of affective adaptation. Perspectives on Psychological Science, v. 3, n. 5, p. 370-386, 2008.

ZAICHKOWSKY, J. L. Measuring the involvement construct. Journal of Consumer Research, v. 12, n. 3, p. 341-352, 1985. 